\title{
A DEMAND - AND SUPPLY- SIDE CONSTRAINED MODEL FOR LIQUIDATION VALUE AND RELATED EXPOSURE PERIODS
}

\author{
Vladimir B. Michaletz, Ph.D. Eng. \\ Russian Society of Appraisers \\ e-mail:mihail-mmm@mail.ru
}

\author{
Andrey Artemenkov, Ph.D., MRICS, (Israel) \\ International Valuation Centre (IVC) \\ State University of Management \\ e-mail:achudakhin02@gmail.com
}

\begin{abstract}
Two problems appear to be most topical in conjunction with mortgage valuation practices during an economic crisis: the assessment of sustainable long-term mortgage values and the assessment of liquidation discounts to prevailing market values which would provide for the most advantageous liquidation/quick sale strategy. This paper addresses the latter issue, which has traditionally proven intractable to analytical modeling. Apart from reviewing some research devoted to the subject of liquidation value modeling, predominantly from the Eastern European perspective, where this issue has, for years, commanded a particular economic interest, this paper synthesizes the best features of this research and builds on it to propose its own model, which lays equal emphasis on both the sellerside and demand-side perspectives. The first perspective accounts for the financial interests of a lender in forced sale disposals, while the latter perspective engages economic analysis on the side of market feasibility of identified efficient lender disposal strategies. By negotiating both perspectives, an optimal analytic solution to the issue of liquidation value discounts can be obtained. This is achieved by what we call a SI-MI framework which is developed throughout the paper.

We also adapt this framework specifically to the mortgage banking context where we use it to bring to light some rarely discussed linkages between the LTV policies of a bank and its mortgage liquidation strategies. This also allows us to propose a model and an LTV formula which can help organize thinking about optimal LTV policies in credit issuing processes.

We hope that, with the re-appearance of liquidation value basis/premise of valuation as a recognized international basis of valuation in the new edition of the International Valuation Standards (IVS 2017), the findings of this paper will become topical.
\end{abstract}

Key words: Liquidation value, forced sale discounts, optimal exposure periods, seller indifference (SI) curve, market indifference (MI) curve, optimal LTV ratios, Time-on-the-market elasticities.

JEL Classification: D46, D49, R39.

Citation: Michaletz V.B., Artemenkov A., 2018, A Demand - and Supply - Side Constrained Model for Liquidation Value and Related Exposure Periods, Real Estate Management and Valuation, vol. 26, no. 2, pp. 48-59.

DOI: $10.2478 /$ remav-2018-0015

1. The concept of liquidation value and liquidation value analysis in appraisal literature

In the International Valuation Standards (2017 edition), the basis of liquidation value is now explicitly recognized and defined as: 
"Liquidation Value is the amount that would be realized when an asset or group of assets are sold on a piecemeal basis. Liquidation Value can be determined under two different premises of value: (a) an orderly transaction with a typical marketing period, or (b) a forced transaction with a shortened marketing period." (IVSC 2017, Standard 104, par. 80.1).

The paper considers a model for the liquidation value basis in its second (b) sense -- as the basis of valuation which presumes a hypothetical transaction between the specific time-constrained seller and a hypothetical market participant acting as an unrelated party. In this sense, and abstracting from the piecemeal qualification in the cited IVSC definition ${ }^{1}$, liquidation value basis has long been recognized as the standard of value in North America (e.g. see CAMPBELL et al. (2009)) and referenced in the USPAP valuation standards (under "Value" in the "Definitions" Section)2.

The area of liquidation value studies is dominated by meticulous empirical-style research, such as the CAMPBELL et al. (2009) survey conducted for the state of Massachusetts, wherein a subset of foreclosure-driven and other distressed transaction data has been distilled from the "general universe" of recent historical property sales in this state, with the economic features of this subset being directly analyzed -- including the average liquidation discount and its scatter ${ }^{3}$. Such studies offer an excellent bird's eye view of the market terrain and its variation, without explaining what rational (or irrational) processes caused such and such discount to vary within relatively wide margins identified by the study. For this explanation we need an analytical approach to, or a deductive analysis of, liquidation price setting, which is not the usual aim of statistical studies. On the deductive analysis front, the liquidation price setting process has been subjected to some studies predominantly of a qualitative and descriptive nature (e.g. DERBES et al. 2001; ROSLOV et al. 2003; GALASYUK, GALASYUK 1998). The descriptive character of these analyses still falls far short of any applied analytical pricing models. To our knowledge, the quantitative deductive-analytical side of research in this area all but remains scant. The only exhaustive account given to it in some time is related to the consideration of what we call "seller-side indifference conditions" (e.g. see GALASYUK, GALASYUK 2007; KOZYR (2001)4, such that make it advantageous for a distressed seller to discount his price - provided that the smaller consideration he gets in exchange is capable of compounding in his investment portfolio to the normal market price level over the period lapsing between the estimated date of the distressed sale and the ending of the normal market exposure period characteristic of market value 5 . The envisaged end result is thus such that the seller financially benefits in equal measure either from pursuing this quicker liquidation strategy at the distressed price or from sticking to his marketing strategy with the market value level, requiring greater exposure periods.

In Eastern Europe, this consideration underlies what is nowadays a conventional recommendation for developing - via a present value discounting factor -- liquidation discounts to market value, and also brings us to the operational distinction of liquidation value vis-à-vis market value, which is illustrated in Fig. 1.

\footnotetext{
1 This Paper considers the disposal of assets in isolation and avoids what are termed in the IVSs "the unit of account" considerations.

2 In official legal language, the concept of liquidation value, which we also take to be synonymous with the distressed or forced sale value (where the principal constraint is that of time), is defined as follows: «The most probable price that a specified interest in real property is likely to bring under all of the following conditions: 1)Consummation of a sale will occur within a severely limited future marketing period specified by the client; 2 ) The actual market conditions currently prevailing are those to which the appraised property interest is subject; 3 ) the buyer is acting prudently and knowledgeably; 4) The seller is under extreme compulsion to sell; 5) The buyer is typically motivated; 6) The buyer is acting in what he or she considers his or her best interest; 7) A limited marketing effort and time will be allowed for the completion of a sale; 8) Payment will be made in cash in U.S. dollars or in terms of financial arrangements comparable thereto. 9) The price represents the normal consideration for the property sold, unaffected by special or creative financing or sales concessions granted by anyone associated with the sale». (From The dictionary of Real Estate Appraisal, 4 ed., The Appraisal Institute 2002)

3) This wide-ranging statistical study finds bank foreclosure discounts to be particularly large - on average at $28 \%$ - of the values of a house in orderly sales.

4 Elsewhere known (e.g. in GALASYUK, GALASYUK (2007)) as "the principle of loss-preventive realization of property at a price less than its market value".

${ }_{5}$ After describing the seller-side considerations in words, we will review the analytic mechanism of associated adjustment in a few passages below.
} 


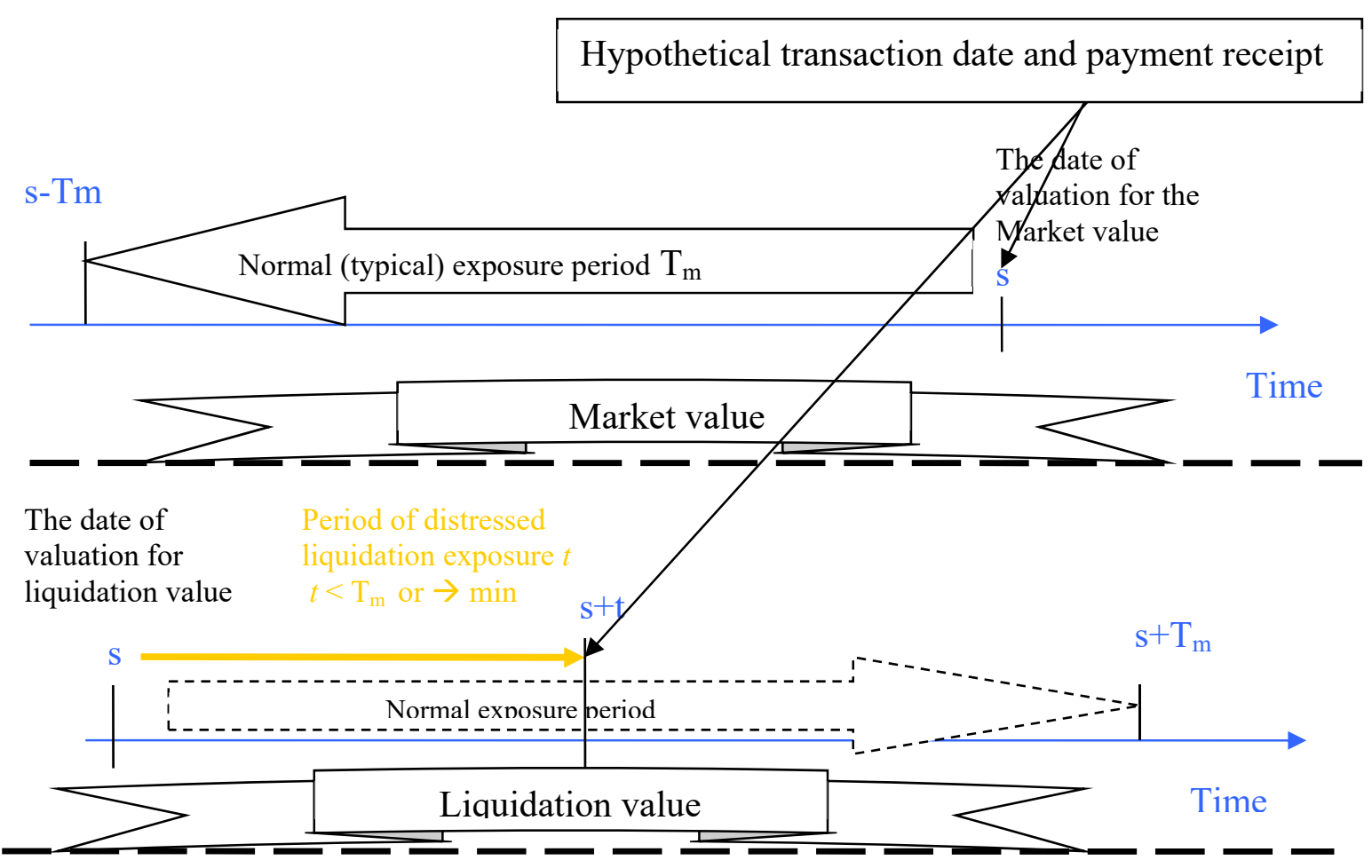

Fig 1. Differences between the Market value and Liquidation value concepts (symbols: $s$ - the date of valuation; Tm - normal market exposure period characteristic of market value; $\mathrm{t}$ - liquidation value exposure period (in a distressed sale, $\mathrm{t} \leq \mathrm{Tm}$ ). Source: own study.

In connection with identifying an important distinction between market value and liquidation value, which is not usually stressed in literature, we note that, according to the international application of the market value base (as defined by IVSC), the marketing period in a hypothetical transaction under market value precedes the valuation date ${ }^{6}$. There is a justification for this convention - since, in relying on the record of comparative sales whose exposure to the market preceded the date of transaction, there is no reason for the sake of consistency to suppose that the pattern should be different in respect to the most frequent market-grounded comparative basis of value specification (i.e. market value). However, the matter is different for the liquidation value basis. Here the limited market exposure period $(t)$ follows the date of valuation made on the liquidation value basis rather than preceding it. The nature of the conventional liquidation discount adjustments directly attests to this view: in so far as we can discount to present value only those receipts which follow in time after the present, the nature of value to which a discounting liquidation factor is applicable also relates to some future date. Thus, the liquidation discount applies to a prospective market value $\mathrm{Vm}_{\mathrm{s}+\mathrm{Tm}}{ }^{7}$ (see Fig 1 for notation). Proceeding from an estimate of $\mathrm{Vm}_{\mathrm{s}+\mathrm{Tm}}$, the possible set of liquidation prices $\mathrm{V}_{\mathrm{L}}$, depending on a chosen specific liquidation exposure period $t$, can be derived using the mentioned seller-side indifference principle. The rationale for this adjustment process can be developed in greater detail in Section 2.

\section{Formalizing seller-side constraints in the model}

When selling a property at a price that corresponds to its market value, it is necessary to undertake its exposure to the market during a relatively long period of time, Tm. If the intention is to sell the property quicker $(t<\mathrm{Tm})$, its seller has to compromise on the price to make it more attractive to the

\footnotetext{
${ }^{6}$ See IVS 104 standard p. 30.20 (g) in the International Valuation Standards 2017 (IVSC, London, 2017).

7 Nonetheless, $\mathrm{Vm}_{\mathrm{s}+\mathrm{Tm}}$ can be proxied by the current market value $\mathrm{Vm}$ at time $s$. One of the modeling assumptions of this paper which will become evident later on in the text is precisely the assumption that $\mathrm{Vm}$ does not vary in time over the Tm period subsequent to the valuation date $s$. Otherwise, it is here that the matter of Vm variability over time links up with the MLV facet of the banking valuation process and related debate, which, as was mentioned in the opening remarks, we consciously left out of the scope of this paper.
} 
market. What tactic should be used for this? One proper tactic amounts to the following: one sells the property at a price less than $\mathrm{Vm}_{\mathrm{s}+\mathrm{Tm}}$, and invests the proceeds of their sale into their investment portfolio or a bank so that, by the termination of the normal exposure period, Tm, they will have had some interest compounded on it. In this case, one's total sale revenue will consist of two components: 1) the amount of proceeds received directly from the buyer and 2) the amount of interest accumulated on the proceeds -- from the pursuance of the subsequent investment strategy. If this total sale revenue at time s+Tm doesn't fall short of the market value amount $\mathrm{Vm}_{\mathrm{s}+\mathrm{Tm}}$, it means that the seller-side indifference principle is being satisfied. Again, the essence of this principle can be illustrated graphically in Fig 2, which reflects the following: a distressed seller trying to obtain the best revenue from the sale of his property (corresponding, under conditions of market competition, to its market value $\mathrm{Vm}_{\mathrm{s}+\mathrm{Tm}}$ ) could receive it in the form of the two just mentioned components: the component corresponding to liquidation value of the property $\left(\mathrm{V}_{\mathrm{L}}\right)$ and the component $\Delta\left(\mathrm{r}, \mathrm{T}_{\Delta}\right)$ representing income which accrues over the period $\mathrm{T}_{\Delta}$ from investing the proceeds of $\mathrm{V}_{\mathrm{L}}$ into a specific available investment strategy (or reinvesting into the seller's main business) which returns interest at the annual rate $r$ over that period ${ }^{8}$.

Thus,

$$
\mathrm{Vm}_{\mathrm{s}+\mathrm{Tm}}=\mathrm{V}_{\mathrm{L}}+\Delta\left(\mathrm{r}, \mathrm{T}_{\Delta}\right) .
$$

This income $\Delta\left(\mathrm{r}, \mathrm{T}_{\Delta}\right)$ from investing the proceeds from sale at a liquidation value can be estimated using the following compounded interest formulae:

$$
\Delta\left(\mathrm{r}, \mathrm{T}_{\Delta}\right)=\mathrm{V}_{\mathrm{L}} *\left((1+\mathrm{r} / \mathrm{m})^{\mathrm{T}^{\Delta *} \mathrm{~m}}-1\right),
$$

where the additional symbols are: $r$ - the interest rate projected for the investment strategy (per annum); and $m$ - the number of interest-compounding periods annually.

Substituting $\Delta\left(\mathrm{r}, \mathrm{T}_{\Delta}\right)$, determined according to expression (2) into expression (1), we obtain:

$$
\mathrm{Vm}_{\mathrm{s}+\mathrm{Tm}}=\mathrm{V}_{\mathrm{L}}{ }^{*}(1+\mathrm{r} / \mathrm{m})^{\mathrm{T}^{\Delta *} \mathrm{~m}}
$$

or, representing the above equation for $\mathrm{V}_{\mathrm{L}}$, it obtains that:

$$
\mathrm{V}_{\mathrm{L}}=\mathrm{V}_{\mathrm{m}_{\mathrm{s}+\mathrm{Tm}}} \frac{1}{(1+\mathrm{r} / \mathrm{m})^{\mathrm{T} \Delta^{*} m}}
$$

The fraction on the right-hand side of Equation (4) represents one rational way of establishing what can broadly be called the "liquidation discount adjustment" (LDA) to market value. That is,

$$
\mathrm{V}_{\mathrm{L}}=\mathrm{Vm}_{\mathrm{s}+\mathrm{Tm}} * \mathrm{LDA}
$$

LDAs obtained that way will represent a general formulation and admit of various modifications and refinements for transaction and holding costs along with some other factors. However, it will later be shown that their derivation in this manner reveals only a part of the picture.

It follows that with LDAs derived using the above principle of the seller-side financial indifference, a distressed seller is financially indifferent to either trading property at $\mathrm{V}_{\mathrm{L}}$ at time $s+t$ or to having to wait longer until a "normal" time $s+T m$ when he can expect to dispose of his property at Vm - its market value. The trade-off between $V_{L}$ and Vm satisfying the seller-side indifference condition on which the LDAs are based is shown by the SI curve in Fig. 2 . The SI curve shows a seller his financially neutral set of options to transact at any time-point of this SI curve at a price indicated by the curve. Transactions in the region of the graph above the SI curve represent an area providing an extra financial advantage to the seller, whereas transactions concluded in the regions below the SI curve are the loss-making transactions for the seller, which he should strive to avoid. It is to be additionally stressed that this curve illustrates the impact of the financial-indifference-principle based LDAs for a specific fixed interest rate $r$ only. Otherwise, there would have to be a three-dimensional picture.

\footnotetext{
8 In real life applications, the calculation is not so sensitive to a specific magnitude for $r$ due to the fact that, for most property types, $\mathrm{T}_{\Delta}$ is a period of limited duration (always less than the normal marketing exposure period). We refrain from suggesting a specific technique for estimating $r$, but for those sellers who are not sophisticated investors or do not have their business, this rate $r$ can be assumed to be equal to customary interest offered on a bank deposit.
} 


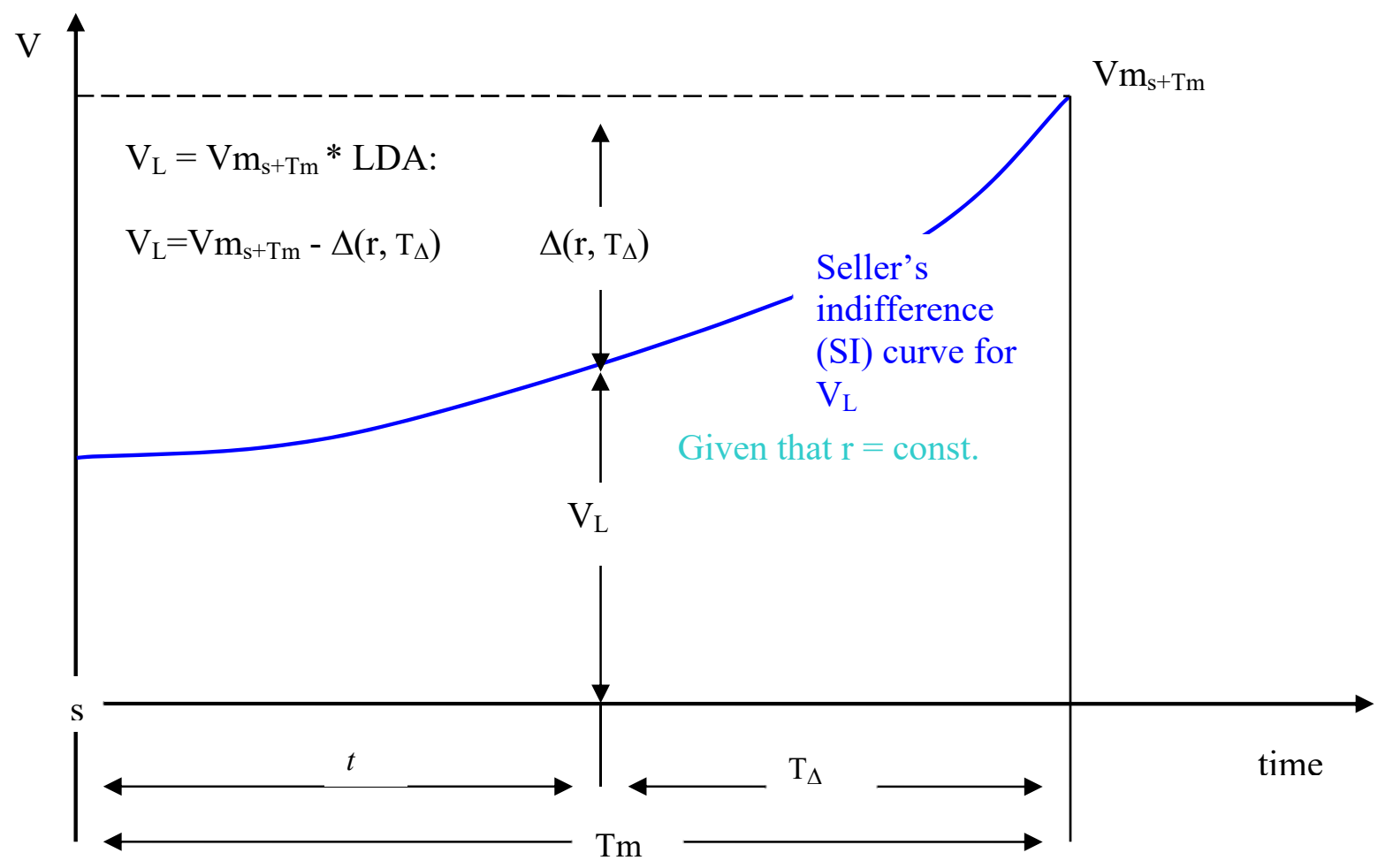

Fig 2. Graphical interpretation of the seller-side indifference adjustment, where: s- the present time; $\mathrm{Tm}$ - normal market exposure period; $t$ - distressed liquidation exposure period; $\mathrm{T}_{\Delta}$ - the discounting period; $\mathrm{V}_{\mathrm{L}}$ - liquidation value corresponding to a specific $t$-period with the relation depicted by the SI curve; $\Delta\left(\mathrm{r}, \mathrm{T}_{\Delta}\right)-$-- income which is derived over the period $\mathrm{T}_{\Delta}=\mathrm{Tm}-t$ from the accumulated interest/yield in an investment strategy pursued by the distressed seller, the rate of accumulative interest being $r$. Source: own study.

So far, two important corollaries follow from discussing the liquidation value estimated on the basis of the seller-side financial indifference principle. First, it cannot be emphasized enough that the liquidation discounting factor LDA is formally applied to the prospective market value $\mathrm{Vm}_{\mathrm{s}+\mathrm{Tm}}$. (at the time $s+T m$ ), and while the current market value $\mathrm{Vm}$ at time $s$ estimated using observable transaction data can, out of necessity, be used as a proxy for this, it unavoidably introduces an additional element of speculative uncertainty into the estimating framework for $\mathrm{V}_{\mathrm{L}}$. Secondly, contra to occasional preIVS 17 claims that liquidation value is an "irrational" basis of valuation, it is worth noting that, in the above estimating framework for the liquidation value, there is nothing to suggest that the transactionrevenue-maximizing interests of a property vendor are breached (on the contrary, conscious account is made of them on the basis of the seller-side financial indifference principle, albeit disregarding prospective uncertainty and the speculative elements over the future time Tm) or that the relation existing between the market value and liquidation value is merely a coincidental one (at this point in our discussion the identified relation is still in the form of a curve, but not haphazard).

\section{Introducing demand-side constraints in the model.}

Modelling of demand-side Liquidation value constraints can proceed on the basis of the empirical concept of Time-on-theMarket (TOM) elasticity. The study of this micro-level elasticity (not to be confused with demand elasticities of macro-level property market studies) does not go unnoticed in property literature; in fairness, there have been more than a dozen prominent studies related to different regional property markets (mostly in the US and Canada), e.g. YAVAS, YANG 1995; JUD et al. 1996; ANGLIN et al. 2003; BJÖRKLUND et al. 2004; CHEN, Ho 2010; CIRMAN et al. 2015. These studies, which span a period of more than the past 20 years, are all statistic-empirical in nature and many of them aim to chart the dependence of time-on-the market (TOM) as a dependent variable for residential properties, regressing it on various factors of interest. One such universally important 
regressor factor that researchers usually identify in TOM models is the degree-of-overpricing (DOP) variable for properties in the sample, defined as the deviation of the actual property listing price from the "optimal price" 9 which (in the absence of independent appraisals for each item in the sample) in turn is itself, however, usually determined by falling back on complex subsidiary regression models of the subject property market (for example, this approach is pursued in ASABERE et al. (1993), ANGLIN et al. (2003), to some extent JUD et al. (2006), where probit models are used instead of regressions, and BJORKLUND et al. (2004), CIRMAN et al. (2015), both of which find the impact of DOP on TOMs to be a statistically significant one $\left.{ }^{10}\right)$. Empirical elasticity values that can be gleaned from such and associated analyses would be most immediately relevant in the context of our demand-side model.

Thus, for the sake of clarity, as the term is usually used, time-on-the-market elasticity (Elt) can conceptually be defined as:

$$
E l t=\frac{d t}{d V} \cdot \frac{V}{t},
$$

i.e. denoting, in statistical terms, the percentage change in time-on-the-market for a property $(t)$ in response to $1 \%$ change in the price $(V)$ of the property.

Supposing that the requisite TOM elasticity estimates for a specific market segment are at hand (e.g. by having valuers develop their own estimates of such elasticity on the basis of property listing service data or by opting to use pertinent published TOM elasticity estimates, e.g. from surveys quoted above and the like, as a rough substitute), the question now arises, how to incorporate them into the analytical framework for estimating liquidation values or LDAs?

To mention one precedent for using TOM elasticities in valuation practice to assess liquidation values, one technique for doing this, which has purportedly gained some recognition in Ukraine and some CIS states over the years, was developed in GALASYUK and GALASYUK (2007). Its essence is to adjust the LDA factor developed along the lines of the previous section by an additional demandelasticity parameter Ke of a multiplicative form, such that:

$$
\mathrm{V}_{\mathrm{L}}=\mathrm{Vm}_{\mathrm{s}+\mathrm{Tm}}{ }^{*} \mathrm{LDA} * \mathrm{Ke}
$$

It is maintained in GALASYUK and GALASYUK (2007) that the relation between the TOM elasticity and the Ke parameter can be elicited by the use of this formula:

$$
\mathrm{Ke}=\operatorname{th}|\mathrm{El}|=\frac{\mathrm{e}^{|\mathrm{Elt}|}-\mathrm{e}^{-\mid \text {Elt } \mid}}{\mathrm{e}^{|\mathrm{Elt}|}+\mathrm{e}^{-\mid \text {Elt } \mid}}
$$

where:

th $(x) \quad$ - is the hyperbolic tangent function;

| Elt | - TOM elasticity (absolute value regardless of the sign); e $=2.71828$ (const).

Another similar approach incorporating demand-side elasticities is that of ROSLOV et al. (2003).

Although the GALASYUK and GALASYUK (2007) recommendation to use this hyperbolic tangent approach for incorporating the demand-side elasticity constraint into the LDA assessment process appears to have some empirical basis ${ }^{11}$ and, if widely used, becomes self-fulfilling, this paper suggests

\footnotetext{
9 i.e. the notion functionally resembling the appraisal market value

${ }_{10}$ The later Cirman Paper for the Slovenia (Ljubljana) property market assesses that a 1 percent increase in DOP results, on average, in a 1.10 percent increase in TOM, isolating for other factors. Other similar surveys found both positive and even negative (BJORKLUND et al. 2004) elasticity estimates. Other authors, on logical grounds, postulate that TOM elasticities change their sign along the length of the curve, i.e. the relationship between the price achieved and the time on the market for property has a hump on the curve - excessive exposure periods far from helping sellers achieve superior prices may have a blight effect on them (BJORKLUND et al. 2004; CIRMAN et al. 2015). This paves the way for introducing the concept of optimal TOM on which the market value standard is presumably based (see ASABERE et al. (1993)) for attempts to derive optimal TOMs using a constrained optimization framework)

11 The justification for this function is largely empirical: observed practice samples which were used in elaborating the form of the Ke function provide evidence of the best fit/least error when a functional specification in the form of the hyperbolic tangent curve is chosen to bridge the difference between the observed liquidation
} 
a less rigid approach urging valuers undertaking liquidation value assignments to chart the TOM dependence, or estimate related elasticities directly or assume them by referring to applicable academic surveys.

Having knowledge of TOM elasticities estimated in the neighborhood of characteristic market exposure periods $(\mathrm{Tm})$ and market values $(\mathrm{Vm})$ - as is likely to be the case in the academic market surveys quoted above-a direct formal analysis of the TOM elasticity notion would help yield the shape of the functional relation between TOM ( $t$ - as measured in days on the market) and listing prices ( $V$, in currency units) in the neighborhood of $T m$ and $P m$ points (see Appendix 1 for a demonstration of the derivations $\left.{ }^{12}\right)$ :

$$
V=V_{m} \cdot\left(\frac{t}{T m}\right)^{1 / E l t} .
$$

This formula means that the value of an item in a distressed sale with the exposure period $t$, with $t$ being less than the normal market exposure period $T m$, depends on the ratio between these two exposure periods, as well as on TOM elasticity Elt. It is to be emphasized that Formula (10) plays the same role on the demand-side of the analysis as Formula (4) does on the seller-side.

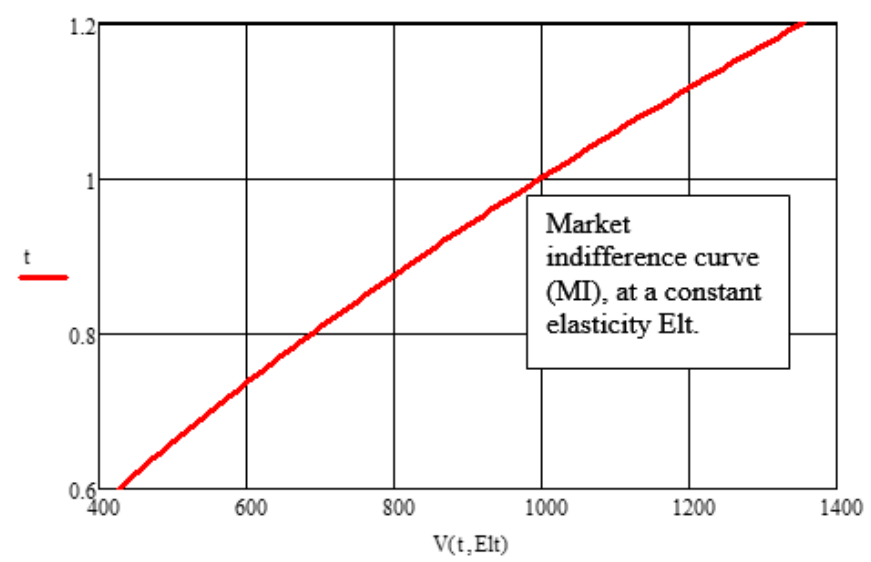

Fig. 3. The market indifference curve V(t, Elt) for an inelastic market where: $\mathrm{Vm}=1000, \mathrm{Tm}=1$, Elt $=$ 0,6 . Source: own study.

As an example, a curve illustrating Formula (14), given that $\mathrm{Vm}=1000, \mathrm{Tm}=1$, Elt $=0.6$ is presented in Fig. 3 . For symmetry with the SI-curve, we shall call this curve the "market indifference curve", or MI-curve. It shows the boundary condition for the effectuation of transactions on market terms, that is, transactions can be successfully completed (be "market-feasible") in the regions above this curve (with $\mathrm{V}$ marked on the $\mathrm{x}$ - axis) or below this curve (with $t$ on the $\mathrm{x}$-axis). The MI curve is always linear for unitary elasticity $(E l t=1)$, but its shape is non-linear (either upward sloping or sagging) in all other cases. A real-life MI curve is cut off towards origin by some minimally possible exposure period and cannot reach all the way down to zero, since there is always some time involved in the preparation of a market sale, and one cannot sell a house on the market in less than a day. In that sense, liquidation value is the market price, but not some negotiated price between related parties who are known to each other and have agreed to oblige each other on whatever terms beforehand.

Thus, the resulting analytical framework is one where an individual seller's financial interests are confronted and harmonized with the prevailing terms of overall market demand. Indeed, the SI-curve characterizes the motives of a particular seller, whereas the MI-curve permits an interpretation as an

sale price and its SI curve-based estimate at $t$ specific to each sampled sale, with samples including various broad categories of consumer goods, property, and plant and machinery assets (however the exact details of sample testing have not been published by the authors).

12 The Appendix contained in the full version of this Paper derives this formula but has been omitted here due to space constraints required by REMV. 
aggregate market demand curve (with exposure periods generally bearing the inverse relation (but not in the form of a strict inverse in the mathematical sense $(Y=1 / X) !)$ to the transaction intensities).

There is plenty of room for elaborating this kind of analysis and developing specific versions of it, fit for various cases. We consider one such accommodation of the MI-SI analysis below for the banking context.

\section{A liquidation value model for banking analysis (nexus with LTV ratios)}

In this section, we develop a version of the proposed MI-SI approach for estimating liquidation values of a mortgage security (pledge) provided that its loan-to-value (LTV) ratio is known, or for developing optimal LTV ratios for a bank loan policy provided that the bank follows a specific liquidation process with known liquidation exposure ratios $\mathrm{t} / \mathrm{Tm}$. Again, here, as elsewhere throughout the text, one principal underlying assumption bears repeating: the prospective longer-term uncertainty, where it inevitably affects the model variables, is left out. Thus, the model holds only to the extent this assumption is considered reasonable, which can only be in a short-term context.

First, we offer a more detailed specification for the SI- function in this banking context.

From the point of view of a lender, who is compelled or is interested to sell a pledged property quicker than is the usual exposure time for such properties but with no financial damage to himself, the liquidation value can be assessed using the following SI function:

$$
V_{\mathrm{L}}=\frac{C_{k}+Z_{r}}{(1+r)^{\left(T_{m}-t\right)}}=\frac{V_{m}(1-d)+V_{m} z}{(1+r)^{\left(T_{m}-t\right)}},
$$

where: $C \kappa$ - the amount of property-secured loan outstanding, as it appears at the beginning of mortgage repossessing procedures; $\mathrm{Zr}$ - foreclosure and attendant forced sale costs; $d$ - complement of the LTV ratio $\left(\mathrm{LTV}^{13}=1-d\right) ; z$ - foreclosure and attendant forced sale costs expressed as a percentage of the market value of property; $V m$ - market value of the pledged property (its temporal reference point is the same as for $C \kappa) ; r$ - the discount rate (alternative investment return on receipts obtainable from the sale of property); Tm - normal (most likely) market exposure period for the property at a price corresponding to its market value; $t$ - liquidation or desired exposure period.

The meaning of this formula (11) is that the lender, desiring to recover his money (the amount of loan outstanding at default $C_{\kappa}+$ foreclosure and liquidation costs $Z r$ ) in time $t$ after the default, should assign an asking price for the pledged property such that the receipts obtained from selling at this price will have grown in the investment environment of the lender's business over the remaining time $\operatorname{Tm}-t$ (i.e. $\mathrm{T}_{\Delta}$ ) to the amount "C $\kappa$ (loan) $+\mathrm{Zr}$ (liquidation costs)», i.e. the amount sufficient to compensate the lender for his default losses. Therefore, by disposing of a mortgaged property on the terms implied by any of the points on the SI curve, the lender is financially indifferent (immune) to the default situation and always recovers the full outstanding amount of the loan.

Combining this SI specification, in which the ratio $\mathrm{t} / \mathrm{Tm}$ is the variable factor around which the solution is developed, with the MI curve - for example, the one shown in Fig. 3 -- we come to the solution of the liquidation value problem. Using specification of the MI curve from Fig. 3 and additionally being given a situation where LTV $=85 \%$, liquidation costs $z=10 \%$, and the market value of property $\mathrm{V} m$ is 1000, we illustrate the solution in Fig. 4.

On the other hand, having curves which do not intersect is not unusual: quite often the curves fail to intersect at $\mathrm{t} / \mathrm{Tm}<1$, indicating a situation where the state of the market would not permit a lender to dispose of the pledged item in time less than the normal marketing period without, at the same time, incurring a financial loss. A situation of this type is depicted in Fig.5. This, we perceive, is one of the reasons underlying the pre-IVSs 2017 international strictures on the indiscriminate use of the liquidation, or forced sale, values. Indeed, if the liquidation value estimation process is carried out arbitrarily without appreciating some inherent economic trade-offs involved, it has a capacity to inflict a by no means negligible financial damage on all the parties to the valuation.

\footnotetext{
${ }^{13}$ In our case the LTV ratio is based on the market value of the pledged property.
} 


$$
\begin{aligned}
& \operatorname{SI}(t)=-\frac{\operatorname{Vm}(1-d)+\operatorname{Vm} z}{(1+\mathrm{f})^{(\operatorname{Tm}-t)}} \\
& \mathrm{NI}(\mathrm{t}, \mathrm{E} 1 \mathrm{t})=\mathrm{Vm}\left(\frac{\mathrm{t}}{\mathrm{Im}}\right)^{\frac{1}{\mathrm{E}}} \\
& \mathrm{Vm}:=1000 \quad \mathrm{Tm}:=1 \quad \text { Elt }:=0.6 \\
& \mathrm{t}:=0.5,0.51 \ldots 1 . \\
& r:=0.25 \\
& z:=0.1 \\
& \mathrm{~d}:=0.15
\end{aligned}
$$

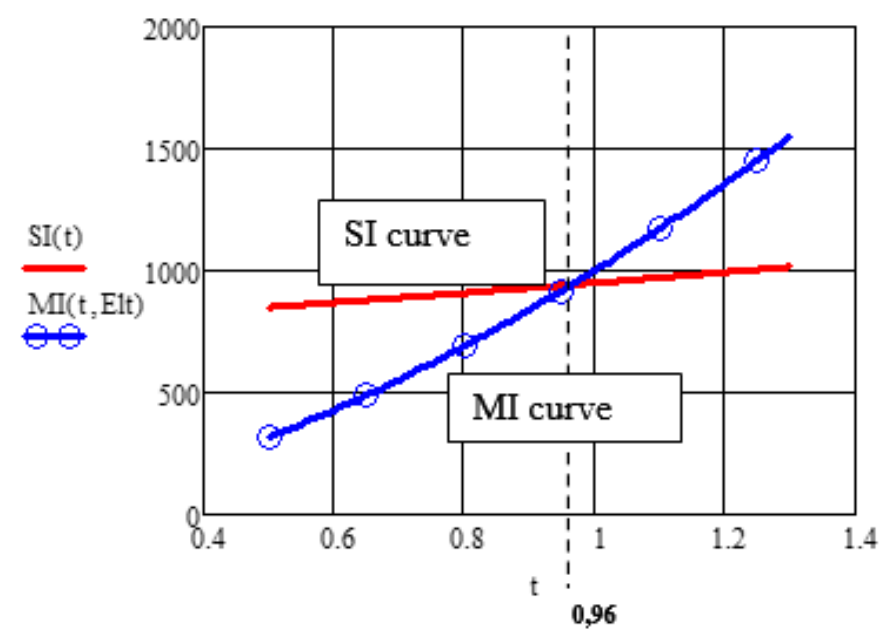

Fig. 4 The market is inelastic (elasticity Elt $=0.6$ ). With liquidation costs $z=10 \%$ of market value, an $85 \% \mathrm{LTV}$, loan can be fully recovered at default within the period $t$ slightly shorter than the normal exposure period $\mathrm{Tm}(t=96 \%$ of $\mathrm{Tm})$ by announcing an asking price of around $\$ 943(\mathrm{t}=0.96 ; \mathrm{MI}=\mathrm{SI}=$ 942.6). Source: own study.

$$
\mathrm{Vm}:=1000 \quad \operatorname{Tm}:=1 \quad \mathrm{Elt}:=3 \quad \mathrm{~d}:=0 \quad \mathrm{t}:=0.2,0.21 \ldots 2 \quad \mathrm{r}:=0.25 \quad z:=0.1
$$

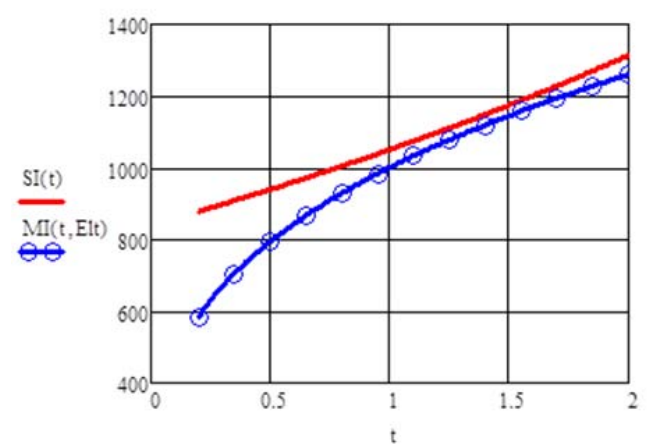

Fig. 5 A scenario in which SI and MI curves fail to intersect: due to a low margin of security (d-z < $0)^{14}$. Source: own study.

In the short-term context (e.g. over the intervals not in excess of $T m$ ), our specification for the lender's SI curve leads to one noteworthy dependence, namely the fact that, when the market admits of liquidation value trade-offs implied in the SI curve, the loan coverage ratio (LTV) of a bank can be coordinated with the aspects of its mortgage liquidation process (strictly speaking, this deduction holds only over short-term periods - in the absence of variation in market values between the date of granting a loan and the potential date of foreclosure on its underlying security). The strength of this dependence is sometimes remarkable:

\footnotetext{
14 In cases when loans are made out on low margins of security $(\mathrm{d}-\mathrm{z}<0)$, the curves can also fail to intersect even at the point of market value, meaning that the financial loss will be incurred all the same even in the course of ordinary disposal because the SI curve, which indicates the states of the lender's immunity to default, is in this instance organically above the MI curve and the market value point.
} 
By equating the functions underlying the SI and MI curves (Formulas (10) and (11)) and assuming that the resulting equation has a solution left of $\mathrm{Tm}$ (the result of this process is tantamount to intersecting both curves and represents an analytical substitute for the graphical solution):

$$
\frac{V_{m}(1-d)+V_{m} z}{(1+r)^{T m-t}}=V_{m} \cdot\left(\frac{t}{T_{m}}\right)^{\frac{1}{E l t}},
$$

we can represent this equation for $d$ - the lender's complement of the LTV ratio. We obtain the following function for $d$ as a result of this:

$$
d=z-\left(\frac{t}{T m}\right)^{E l t} \cdot(1+r)^{T m-t}+1
$$

The strength of a dependence between $d$ and $\mathrm{t} / \mathrm{Tm}$ implied by this function can be illustrated using an example similar to one in Fig. 4. This is shown in Fig. 6, which demonstrates a situation characteristic of an inelastic demand $(\mid$ Elt $\mid<1)$.

Subject to the short-term reference, in a foreclosure process using the market value based liquidation strategy $(\mathrm{t} / \mathrm{Tm}=1)$ the size of $d$ is shown to be principally determined by the amount of foreclosure and liquidation costs $Z_{r}$, but, with the introduction of fire sale strategies (implying $t / T m<$ 1), the exposure ratio $t / T m$ becomes an important determinant of $d$, the reasonable LTV haircut. It is to be stressed that the impact of the exposure ratio, $t / \mathrm{Tm}$, is in proportion to the elasticity of the market and is strongest for the least elastic items. In light of these findings, it seems important that banks take a fresh look on coordinating their LTV policy with their liquidation process, as these two policies do not appear to be independent of each other.

$$
\begin{gathered}
\mathrm{d}(\mathrm{t}, \mathrm{Elt}):=\mathrm{z}-\left(\frac{\mathrm{t}}{\mathrm{Tm}}\right)^{\dot{\mathrm{E}} \mathrm{lt}} \cdot(\mathrm{r}+1)^{\mathrm{Tm}-\mathrm{t}}+1 \quad \mathrm{t}:=0.01,0.011 . .1 \quad \mathrm{z}:=0.60 \\
\text { Elt }: 0.6
\end{gathered}
$$

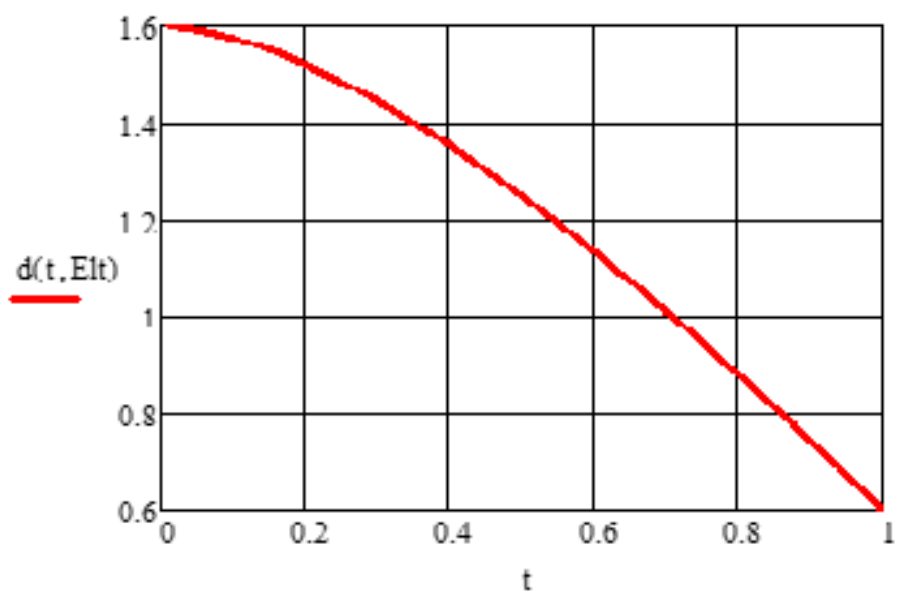

Fig. 6. The dependence of $d(d=1-L T V)$ on the liquidation period $t$. Source: own study.

Some countries of Eastern Europe have bank regulation in place which sets upper limits on the disposal time for foreclosed mortgages. We suggest that such seemingly trifling regulations are not without wide macroeconomic impact - to the extent that they can affect LTV policies in the banking sector, and that their impact should be subjected to closer scrutiny. Traditionally, LTV ratio policy is treated as an instrument of reducing risk or diffusing uncertainty and is studied mostly in this light, we hold that there are other important influencing factors on this ratio even in the absence of any uncertainty. 


\section{S sciendo}

\section{Conclusions}

This paper has proposed a static analytic approach to estimating the liquidation discounts and related exposure periods, and suggested its application to property in the context of mortgage lending. The resulting model is a point-in-time model fit for short-term analyses, where variability in $V m$ (and other variables) over typical exposure horizons can be neglected. Being a static model, it has inherent limitations on incorporating multiple dynamic and uncertainty considerations which are important over longer term periods. Even with these limitations, the model has a potential for further refinements, such as incorporating differences in transaction costs between the orderly market liquidation and abbreviated liquidation scenarios, incorporating the changes in elasticity along the various segments of the transaction intensity curve ${ }^{15}$, fully developing a technique for measuring TOM elasticities, and - in the banking context - introducing the consideration of a borrower's creditworthiness, etc. The scope for such improvements is very broad, and they are all important and essential to make the model a tool that is applicable in practice.

\section{References}

ANGlin P. M., Rutherford R., SPRINGeR T. M., 2003, The Trade-off between the Selling Price of Residential Properties and Time-on-the-Market: The Impact of Price Setting, Journal of Real Estate Finance and Economics, 26(1), 95-111. http://dx.doi.org/10.1023/A:1021526332732.

Asabere P.K., Huffman F.E., MeHDian S., 1993, Mispricing and Optimal Time on the Market. Journal of Real Estate Research, 8:1, pp. 149-156.

BJÖRKLund K., DADZIE J., WiLhelmsson M., 2004, Offer Price, Transaction Price and Time-on-the-market, Working Paper No. 49, Real Estate Economics Department: KTH Infrastructure Royal Institute of Technology attachment/49.pdf.

CAmpbell J., Giglio S., PARAg P., 2009, Forced Sales and House Prices, www.nber.org/papers/w14866 (March 2009).

Cirman A., PAHOR M., Verbic M., 2015, Determinants of Time on the Market in a Thin Real Estate Market, Inzinerine Ekonomika-Engineering Economics, 2015, 26(1), 4-11 http://dx.doi.org/10.5755/j01.ee.26.1.3905

CHEN Jo-Hui C., CHAO-Rung H., 2010, The Effect of Time on Market and Location in the Housing Market: A Case Study in Taoyuan Metropolitan Area, Asia Pacific Management Review 15(2) (2010) 207-221.

Derbes JR., MAX J., DerbeS III, MAX J., 2001, Liquidation Price and Semi-Forced Sellers, The Appraisal Journal January, 2001.

FOMENKO A.N. 2006, A Methodical Approach to Estimating Liquidation Value of Property, The Ocenotsnaya Deyatelnost №1, 2006.

HaNUSHEK E., QUigley J., 1980, What is the Price Elasticity of Housing Demand?, The Review of Economics and Statistics, Vol. 62, Issue 3. (August, 1980), pp. 449-454.

THE InTERnATIONAl VALUATION StadnARDS COUNCIL [IVSC], 2017, The International Valuation Standards 2017 ed. . IVSC: London.

Jud D. G., SeAKs T. G., WinkLeR D. T., 1996, Time on the Market: The Impact of Residential Brokerage. Journal of Real Estate Research, 12(3), 447-458.

GALASYUK V., GALASYUK V., 2007, Opredelenje liquidatsionnoi stoimosti po metody Galasyukov GMLV (Estimation of liquidation value using GMLV concept), 3 ed. Zorja publishing house, Dnepropetrovsk, 2007.

KOZYR Y., 2001, Estimation of Liquidation Value, Voprosi Ocenki №1, 2001, p. 49-51.

\footnotetext{
15 These changes can be gradual or stepped. Some models of liquidation value, e.g. one proposed by V. Roslov, A. Myshanov and I. Podkolzin (2003), hypothesize that we should distinguish at least 2 segments in the MI curve, each with its own specific elasticity - corresponding, loosely, to either owner occupational or speculative type of demand. However, their model doesn't contain anything like an independent seller's side indifference curve (SI), instead they try to incorporate the speculative seller-side motive into determining the locus of the inflection point on the MI curve where it significantly changes its elasticity as attracted buyers shift from the owner-occupational category to speculative re-sellers. This notion of structural shifts in the type of buyers' demand is sustained in A. Fomenko's paper on the liquidation value (FOMENKO, 2006), but this latter author shies away from using the notion of elasticity altogether in his models claiming that this notion is statistically well-nigh impossible to estimate and is , therefore, inoperative.
} 
ORLEANS A., 2014, The Empire of Value: A New Foundation for Economics, translated by M.B. Debovoise , The MIT Press, 2014.

Roslov V., Myshanov V., PODKOlzIN I., 2003, Estimating Liquidation Value for Items with Inelastic Demand, Voprosi Ocenki № 1, 2003, pp. 8-13.

TUCKer C., ZHANG J., ZHU T., 2013, Days on market and home sales, The Rand Journal of Economics Volume 44, Issue 2 Summer 2013, pp. 337-360.

Galasyuk V., Galasyuk V., 1998, On How to Sell Property without Loss at a Price Less than its Market Value (Kak bez ybitkov prodat' tovar po tsene nizhe ego rynochnoi stoimosti), Finansoviye Uslygi № 9-10, 1998.

GALASYUK V., GALASYUK V., 2007, Determination of Liquidation Value under the GMLV Method, Dnepropetrovsk, Zora publishers 2007, (In Ukrainian medium).

YAVAS A., YANG S., 1995, The Strategic Role of Listing Price in Marketing Real Estate: Theory and Evidence, Real Estate Economics, 23(3), 347-368, http:/ / dx.doi.org/10.1111/1540-6229.00668.

ZAMFIR M., Di IORIO J., 2007, Demand for New Housing Units in the Northeast 2002-2005, www.diiorio.us/.../Demand_forNew_Housing_Units_NE\%5B1\%5D.ppt. 